\title{
Minimasi Jarak Tempuh Order Picking pada Gudang dengan Karakteristik Two-Cross Aisle Layout
}

\author{
Minimizing Order Picking Travel Distance on Two-Cross Aisle Warehouse Layout
}

\author{
Eka Kurnia Asih Pakpahan, Roland Silitonga, Anggoro Prasetyo Utomo \\ Program Studi Teknik Industri, Institut Teknologi Harapan Bangsa \\ E-mail: eka@ithb.ac.id, roland@ithb.ac.id, anggoro@ithb.ac.id
}

\begin{abstract}
Abstrak
Kegiatan order picking mengkonsumsi hampir $60 \%$ dari total ongkos gudang. Faktor utama yang membuat hal ini terjadi adalah jarak perpindahan saat order picking dilakukan. Penelitian ini mengambil satu kasus khusus dimana tata letak gudang merupakan two-cross aisle. Untuk menemukan rute order picking dengan jarak perpindahan terpendek, lima algoritma heuristik diterapkan dan dievaluasi berdasarkan jarak perpindahan yang diberikannya. Hasil dari penelitian ini menunjukkan peningkatan efisiensi gudang melalui penurunan jarak perpindahan selama melakukan order picking.
\end{abstract}

Kata kunci: algoritma heuristik, order picking, minimasi jarak perpindahan,

Abstract

Order picking activities consumes almost $60 \%$ of the total warehousing cost. The primary factor affecting this large share is the pick-up travel distance. We take a specific case where the layout of a warehouse is a two-cross aisle and developed five heuristic algorithms to determine pick-up routes. The associated travel distance generated by each algorithm were then logged and compared to determine which algorithm generates the shortest pick-up travel distance. By doing this we managed to improve warehouse efficiency by decreasing the pick-up travel distance.

Keywords: heuristic algorithm, order picking, minimizing travel distance.

\section{Pendahuluan}

Kegiatan pergudangan memainkan peranan penting dalam memastikan efisiensi sebuah sistem rantai pasok, karena pergerakan barang antar rantai, membutuhkan kecepatan informasi persediaan berbagai produk yang disimpan di gudang (Lambert dan Stock, 2001), juga kecepatan keluar masuk barangnya. Pengelolaan gudang umumnya mengatur pelaksanaan lima kegiatan berikut: penerimaan (receiving), pengantaran barang untuk disimpan (put-away), penyimpanan (storage), pengambilan barang untuk dikeluarkan (order picking), dan pengiriman (shipping) (Bartholdi dan Hackman, 2011). Di antara lima kegiatan ini, order picking adalah kegiatan paling penting dari sisi efektifitas dan biaya (Habazin, Glasnovic dan Bajor, 2017). Kegiatan ini menghabiskan hampir $60 \%$ dari total biaya pergudangan akibat jarak perpindahan selama kegiatan berlangsung. Melihat signifikansinya peningkatan efisiensi pada kegiatan ini perlu diberi perhatian khusus.

Aktivitas order picking yaitu suatu aktivitas pengambilan produk dari lokasi penyimpanan berdasarkan pesanan pelanggan (Dukic dan Oluic, 2007). Jarak yang ditempuh saat order picking ditentukan oleh keputusan rute, yang sangat penting dalam mengurangi waktu berjalan (De Koster dan Roodbergen, 2007). Keputusan ini dapat diperoleh melalui metode analitis serta metode heuristik (Roodbergen, 2001). Banyak penelitian menemukan bahwa keputusan routing sulit diselesaikan karena bersifat non polynomial (NP) hard, jikapun dapat diselesaikan, waktu pencarian solusi sangatlah lama. Untuk alasan ini, metode heuristik dikembangkan dan digunakan untuk mendapatkan keputusan routing (Hall, 1993). Penelitian (Oktarina dan Wini, 2008) secara khusus berfokus pada permasalahan penentuan routing untuk order picking, mereka merancang algoritma heuristik dan mengimplementasikannya pada gudang berkarakteristik three-cross aisle. 
Algoritma heuristik yang dikembangkan adalah: (1) s-shaped, (2) largest gap, (3) return-to-home, (4) middle point dan (5) aisle-by-aisle.

Penelitian ini mengambil pendekatan yang sama dengan penelitian (Oktarina dan Wini, 2008) dan menerapkannya pada gudang berkarakteristik two-cross aisle. Penelitian ini melakukan penyesuaian terhadap lima algoritma heuristik dan mengimplementasikannya pada gudang dengan two-cross aisle. Kinerja masing-masing algoritma (dalam ukuran jarak perpindahan) kemudian dicatat dan dibandingkan satu sama lain.

Tulisan ini kami sajikan dalam empat bagian. Bagian 1 berisi pendahuluan dan pengenalan masalah; bagian 2 membahas deskripsi sistem dan desain algoritma; bagian 3 menjelaskan implementasi algoritma serta hasilnya; bagian 4 menyajikan kesimpulan dan bagian 5 menyajikan daftar pustaka yang digunakan dalam penelitian ini.

\section{Deskripsi Sistem dan Rancangan Algoritma}

\subsection{Deskripsi Sistem}

Tata letak gudang merupakan faktor penting yang harus dipertimbangkan ketika mengambil keputusan routing. Pada penelitian ini, kami mengambil kasus di mana tata letak gudang adalah two-cross aisle. Tata letak tersebut diilustrasikan pada Gambar.1.

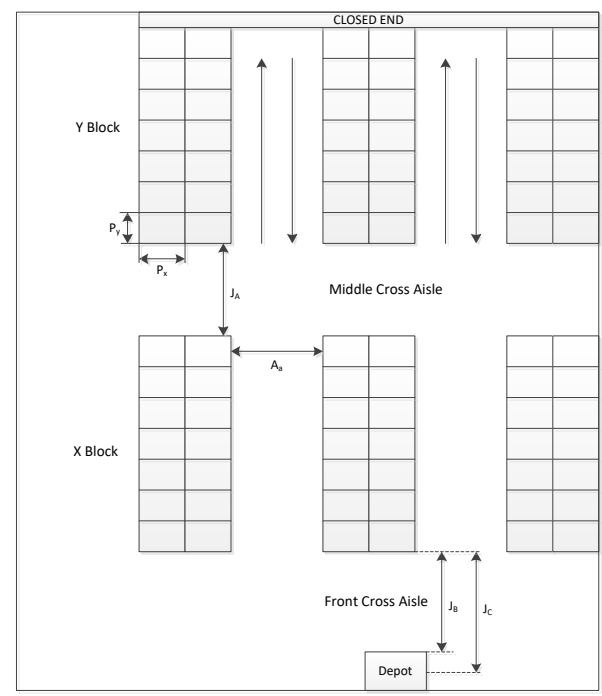

Gambar 1. Gudang dengan Tata Letak Two-Cross-Aisle

Implikasi dari two-cross aisle adalah bahwa pada blok gang tertentu, salah satu ujung lorongnya tertutup. Dengan demikian, peralatan pemindahan material harus berbelok 180 derajat untuk keluar dari lorong.

\subsection{Desain Algoritma}

Pada tahap ini, dikembangkan 5 algoritma heuristik untuk penentuan keputusan routing. Algoritma tersebut adalah s-shaped, largest gap, return-to-home, middle point dan aisle-by-aisle. Jarak yang ditempuh pada setiap rute dihitung menggunakan metode rectilinier. Penjelasan untuk setiap algoritma kami berikan sebagai berikut:

\subsubsection{Algoritma $S$-Shaped}

Berdasarkan algoritma heuristik s-shaped rute order picking ditentukan melalui langkah-langkah berikut:

1. Rute dimulai dari lokasi depot menuju lorong ujung kanan atau kiri berdasarkan jarak terdekat yang memiliki setidaknya satu lokasi pengambilan.

2. Menentukan blok terdekat (blok X) dan terjauh (blok Y) yang dipisahkan oleh middle-cross aisle. 
3. Picker melintasi lorong blok $\mathrm{X}$ hingga sampai pada titik-titik lokasi pengambilan barang dan melakukan pengambilan barang.

4. Picker berjalan terus sepanjang lorong hingga mencapai middle-cross aisle. Terdapat 2 kemungkinan yang dapat terjadi: (a) Terdapat barang yang harus diambil di lorong yang bersesuaian dengan lorong blok $\mathrm{X}$ di blok $\mathrm{Y}$, sehingga picker menyeberang melalui middlecross aisle memasuki blok Y ke lorong yang bersesuaian tersebut. (b) Tidak terdapat barang yang harus diambil di lorong yang bersesuaian dengan lorong blok $\mathrm{X}$ di blok $\mathrm{Y}$, sehingga picker tetap di blok $\mathrm{X}$ dan berpindah lorong di blok tersebut melalui middle-cross aisle.

5. Picker berpindah lorong ke lorong terdekat di blok Y. Mendatangi lokasi pengambilan tersebut melalui middle cross aisle dan berbalik arah setelah mencapai ujung lorong. Ulangi langkah ini hingga seluruh barang yang harus diambil dari blok $\mathrm{Y}$ terpenuhi.

6. Pada lorong paling kiri di blok $\mathrm{Y}$, picker kemudian dapat berpindah ke blok $\mathrm{X}$ dengan melintasi middle cross aisle, sesampainya di blok X, picker dapat menyusuri lorong demi lorong di blok $\mathrm{X}$ melalui middle cross aisle dan keluar dari front cross aisle atau sebaliknya hingga seluruh lokasi pengambilan di blok X selesai.

7. Kembali ke depot.

\subsubsection{Algoritma Return-to-home}

Berdasarkan algoritma heuristik return-to-home, rute order picking ditentukan melalui langkahlangkah berikut:

1. Rute dimulai dari lokasi depot menuju lorong ujung kanan atau kiri berdasarkan jarak terdekat yang memiliki setidaknya satu lokasi pengambilan.

2. Menentukan blok terdekat (blok X) dan terjauh (blok Y) yang dipisahkan oleh middle-cross aisle.

3. Picker melintasi lorong blok $\mathrm{X}$ hingga sampai pada titik-titik lokasi pengambilan barang dan melakukan pengambilan barang.

4. Picker berjalan terus sepanjang lorong blok X hingga mencapai middle cross aisle. Di titik ini, terdapat 2 kemungkinan yang muncul: (a) Picker memasuki blok Y apabila masih terdapat lokasi pengambilan di lorong tersebut dan berbalik arah kembali lalu berpindah ke lorong sebelahnya melalui middle-cross aisle. (b) Langsung berpindah ke lorong sebelah di blok X melalui middle-cross aisle bila tidak ada lokasi pengambilan di lorong terdekat di blok Y.

5. Picker berpindah lorong ke lorong terdekat di blok Y. Mendatangi lokasi pengambilan tersebut lalu berbalik arah menuju middle-cross aisle dan berpindah lorong di blok Y. Ulangi langkah ini hingga seluruh lokasi pengambilan di blok Y terpenuhi.

6. Picker sekarang berada pada lorong ujung kiri yang memiliki lokasi pengambilan, dan akan berpindah ke blok X.

7. Picker memasuki lorong di blok $\mathrm{X}$ yang memiliki lokasi pengambilan. Setelah sampai di titik tersebut, berbalik arah dan berpindah ke lorong sebelahnya melalui middle-cross aisle.

8. Picker berpindah lorong demi lorong yang mempunyai lokasi pengambilan di blok X. melalui middle-cross aisle. Ulangi langkah ini hingga seluruh lokasi pengambilan di blok $\mathrm{X}$ terambil.

9. Kembali ke depot.

\subsubsection{Algoritma Mid-point}

Berdasarkan algoritma heuristik mid-point, rute order picking ditentukan melalui langkah-langkah berikut:

1. Rute dimulai dari lokasi depot menuju lorong ujung kanan atau kiri berdasarkan jarak terdekat yang memiliki setidaknya satu lokasi pengambilan.

2. Menentukan blok terdekat (blok X) dan terjauh (blok Y) yang dipisahkan oleh middle-cross aisle.

3. Picker melintasi lorong blok $\mathrm{X}$ hingga sampai pada titik lokasi pengambilan.

4. Picker berjalan terus sepanjang lorong hingga mencapai middle-cross aisle. 
5. Untuk blok Y, picker mengunjungi lokasi pengambilan melalui middle-cross aisle. Ulangi langkah tersebut hingga seluruh lokasi pengambilan blok Y terpenuhi.

6. Untuk blok $\mathrm{X}$, picker mengunjungi lokasi pengambilan yang berada pada setengah bagian belakang blok melalui middle-cross aisle dan mengunjungi lokasi pengambilan yang berada pada setengah bagian depan blok melalui front-cross aisle. Ulangi langkah tersebut hingga seluruh lokasi pengambilan di blok X terpenuhi.

7. Kembali ke depot.

\subsubsection{Algoritma Largest Gap}

Berdasarkan algoritma heuristik largest gap, rute order picking ditentukan melalui langkah-langkah berikut:

1. Rute dimulai dari lokasi depot menuju lorong ujung kanan atau kiri berdasarkan jarak terdekat yang memiliki setidaknya satu lokasi pengambilan.

2. Menentukan blok terdekat (blok X) dan terjauh (blok Y) yang dipisahkan oleh middle-cross aisle.

3. Picker melintasi lorong blok $\mathrm{X}$ hingga sampai pada titik lokasi pengambilan.

4. Picker berjalan terus sepanjang lorong hingga mencapai middle-cross aisle. Di titik ini, terdapat dua kemungkinan: (a) Picker memasuki blok Y apabila terdapat lokasi pengambilan di lorong tersebut, berbalik arah lalu berpindah ke lorong sebelahnya melalui middle-cross aisle. (b) Picker tetap di blok X dan berpindah ke lorong sebelahnya melalui middle-cross aisle.

5. Saat picker berada di blok Y, perpindahan antar lorong selalu dilakukan melalui middlecross aisle.

6. Saat picker berada di blok X, picker harus selalu membandingkan jarak perpindahan antar lokasi pengambilan pada lorong (gap) blok X dengan mempertimbangkan dua akses jalan, yaitu middle-cross aisle dan front-cross aisle. Terdapat tiga kemungkinan yang dapat terjadi: (a) Nilai largest gap berada pada middle-cross aisle, dengan begitu picker harus mengakses lorong berikutnya melalui front-cross aisle, (b) Nilai largest gap berada pada front-cross aisle, dengan begitu picker harus mengakses lorong berikutnya melalui middlecross aisle, (c) Gap keduanya sama, sehingga picker dapat memilih mengakses lorong berikutnya baik melalui front-cross aisle ataupun middle-cross aisle.

7. Kembali ke depot.

\subsubsection{Algoritma Aisle-by-aisle}

Rute order picking yang dihasilkan algoritma ini hanya akan melewati setiap lorong satu kali. Programa dinamis digunakan untuk menentukan rute terbaik untuk berpindah dari satu lorong pengambilan ke lorong pengambilan yang lain dengan mempertimbangkan jarak terpendek.

Rute order picking dimulai dari depot menuju lorong terdekat. Di lorong tersebut, picker mengambil seluruh barang yang terdapat dalam daftar pengambilan dan keluar melalui front-cross aisle ataupun middle-cross aisle ke lorong pengambilan ke-dua. Pengambilan keputusan didasari jarak tempuh terpendek. Proses ini terus berulang sampai seluruh lokasi pengambilan dikunjungi. Kemudian order picker kembali ke titik awal.

Dalam algoritma aisle-by-aisle ini dikenal istilah transisi untuk menggambarkan cara picker untuk melakukan perpindahan dan pengambilan barang. Transisi menggunakan perhitungan dengan program dinamis. Roodbergen (2001) mengelompokkan transisi ini ke dalam dua kelompok, yaitu: (a) Transisi untuk berpindah dari satu lorong ke lorong lainnya dan (b) Transisi untuk mengambil barang di lorong.

Terdapat satu transisi yang dapat digunakan untuk berpindah dari lorong satu ke lorong lain $\left(t_{a}\right)$, yaitu: melewati front-cross aisle (node a) atau middle-cross aisle (node b). Sementara untuk melakukan pengambilan item pada lorong terdapat tiga transisi yang dapat digunakan, yaitu: memasuki dan meninggalkan lorong dari middle-cross aisle atau node $b\left(t_{1}\right)$; memasuki dan 
meninggalkan lorong dari front-cross aisle atau node a $\left(t_{2}\right)$; memasuki lorong dari front-cross aisle atau node $a$ dan meninggalkan lorong dari middle-cross aisle atau node $b$ atau sebaliknya $\left(t_{3}\right)$.

Misalkan ditentukan notasi-notasi berikut:

$\mathrm{t}_{1} \quad$ : Jarak tempuh jika memasuki dan meninggalkan lorong melalui middle-cross aisle

$\mathrm{t}_{2}$ : Jarak tempuh jika memasuki dan meninggalkan lorong melalui front-cross aisle

$\mathrm{t}_{3} \quad$ : Jarak yang ditempuh jika memasuki lorong melalui front-cross aisle dan meninggalkan lorong melalui middle-cross aisle atau sebaliknya.

$\mathrm{t}_{\mathrm{a}}$ : Jarak yang ditempuh jika melewati front-cross aisle atau middle-cross aisle

$L_{a}^{j} \quad$ : Posisi akhir picker di front-cross aisle untuk lorong $\mathrm{j}$

$L_{b}^{j} \quad$ : Posisi akhir picker di middle-cross aisle untuk lorong $\mathrm{j}$

Penentuan rute dilakukan dengan langkah-langkah berikut:

Langkah 1:

$L_{a}^{j}$ : rute yang dimulai dari node a dan berakhir di node a untuk lorong j dan mengandung transisi $t_{2}$

$L_{b}^{j}$ : rute yang dimulai dari node a dan berakhir di node $\mathrm{b}$ untuk lorong $\mathrm{j}$ dan mengandung transisi $t_{3}$

Langkah 2:

Lorong selanjutnya ditentukan melalui model matematika berikut:

$L_{a}^{j+1}=\min$

- $L_{a}^{j}+t_{a}+t_{2}$

- $L_{b}^{j}+t_{a}+t_{3}$

$L_{b}^{j+1}=\min$

- $L_{b}^{j}+t_{a}+t_{1}$

- $L_{a}^{j}+t_{a}+t_{3}$

Langkah 3:

Lorong terakhir ditentukan melalui model matematika berikut:

$L_{a}^{j+x}=\min$

- $L_{b}^{j+x}+t_{a}+t_{3}$

- $L_{a}^{j+x}+t_{a}+t_{2}$

\section{Implementasi Algoritma dan Perbandingan Kinerjanya}

Kelima algoritma heuristik yang sudah dijelaskan pada sub-bagian sebelumnya kemudian diimplementasikan pada gudang dengan karakteristik seperti pada Tabel 1.

Tabel 1. Karakteristik Gudang Kajian

\begin{tabular}{|l|l|c|}
\hline \multicolumn{2}{|c|}{ Deskripsi } & Dimensi (meter) \\
\hline \multirow{3}{*}{ Lokasi Penyimpanan } & Panjang rak $\left(P_{x}\right)$ & 1.15 \\
\cline { 2 - 3 } & Lebar rak $\left(P_{y}\right)$ & 1.00 \\
\hline \multirow{3}{*}{ Jarak } & Blok X dan blok Y $\left(J_{a}\right)$ & 2.00 \\
\cline { 2 - 3 } & Blok X dengan cross aisle depan $\left(J_{b}\right)$ & 0.75 \\
\cline { 2 - 3 } & Blok X dengan lokasi depot $\left(J_{c}\right)$ & 2.25 \\
\hline \multirow{2}{*}{ Lorong } & Lebar lorong $\left(A_{a}\right)$ & 3.00 \\
\hline
\end{tabular}

Gudang yang akan dikaji berbentuk persegi panjang dan dipisahkan menjadi dua buah blok, yang terdekat dengan depot dinamakan blok X dan yang terjauh dinamakan blok Y. Gudang tersebut memiliki 8 buah lorong penyimpanan barang dan 636 titik lokasi pengambilan. Titik lokasi pengambilan diberi kode secara berurutan mulai dari lorong terkanan: $\mathrm{CA}-\mathrm{CB}$ hingga $\mathrm{CH}$. Dalam sebuah lorong, tersusun rak yang berada di sebelah kanan dan kiri lorong. Bagian kanan dinotasikan dengan angka 01 dan bagian kiri dinotasikan dengan angka 02. Setiap rak memiliki 3 
titik pengambilan dan penamaannya secara berurutan adalah AA-AB-AC lalu BA-BB-BC, dan seterusnya. Saat pengambilan barang, picker berada pada posisi tengah dari rak.

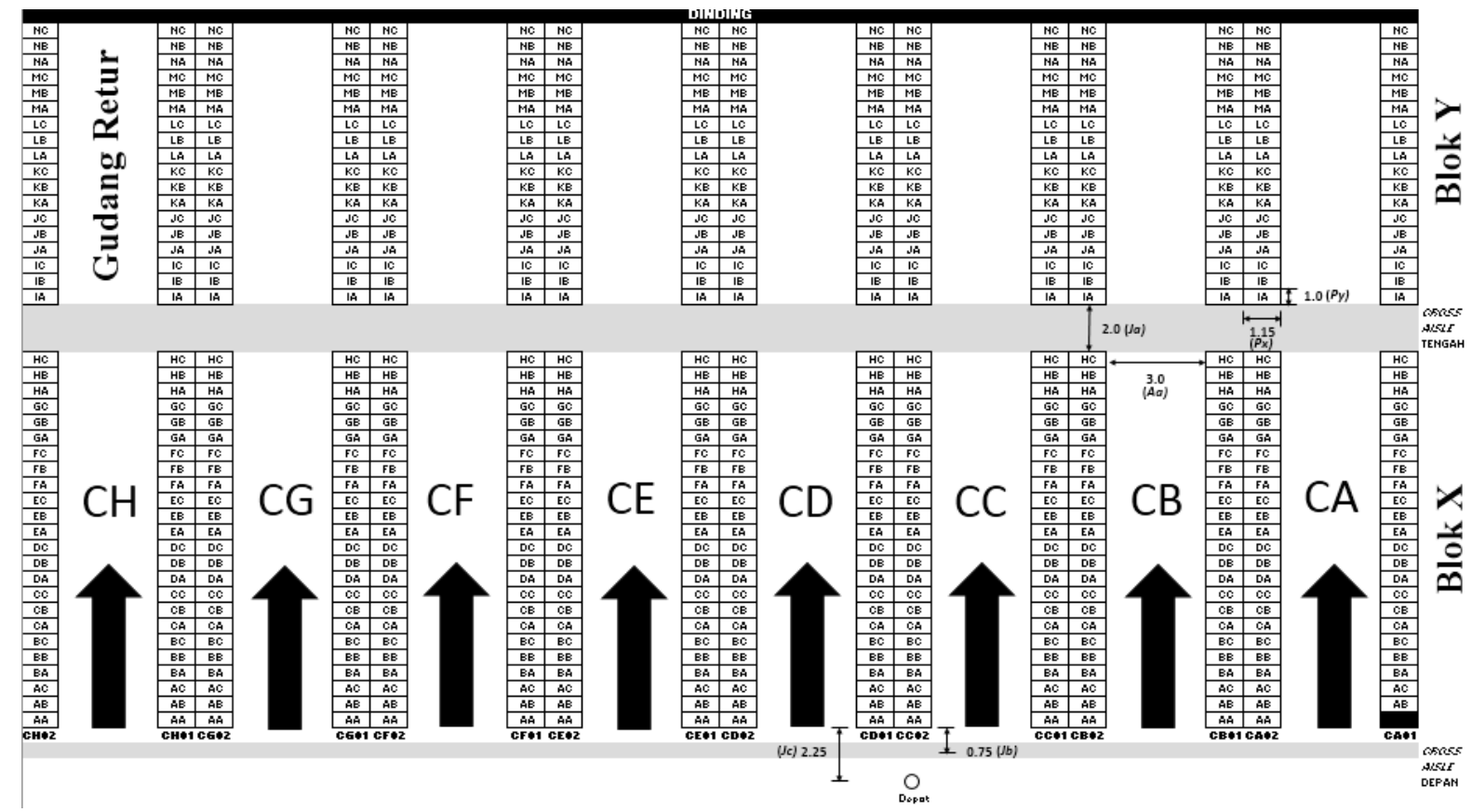

Gambar 2. Tata Letak Gudang Kajian

Task order yang diberikan kepada picker berisi dua puluh jenis barang. Kapasitas pallet diasumsikan tak terhingga sehingga memungkinkan picker mengambil seluruh barang hingga task order terselesaikan. Jarak tempuh picker dihitung dengan metode rectilinear yaitu menurut perpindahan horisontal dan vertikal.

Kelima algoritma kemudian diuji kinerjanya dalam empat kali percobaan. Empat kali percobaan merupakan jumlah sampel yang minimum bagi pengujian ini. Perbedaan antar percobaan terletak pada isi task order yang harus dilakukan picker. Setiap isi task order dibangkitkan secara random dengan bantuan MS. Excel. Mengingat jumlah barang yang harus diambil per task order umumnya adalah 20, maka untuk setiap percobaan dibangkitkan 20 angka random antara 1-636 (menggambarkan lokasi pengambilan barang), spesifikasi isi task order untuk setiap percobaan diberikan pada Tabel 2 hingga Tabel 5.

Tabel 2. Isi Task Order pada Skenario 1

\begin{tabular}{|c|c|c|c|c|}
\hline $\begin{array}{c}562 \\
\text { (CG.02.FA) }\end{array}$ & $\begin{array}{c}358 \\
\text { (CE.01.HA) }\end{array}$ & $\begin{array}{c}407 \\
\text { (CE.02.JB) }\end{array}$ & $\begin{array}{c}140 \\
\text { (CB.02.EB) }\end{array}$ & $\begin{array}{c}555 \\
\text { (CG.02.CC) }\end{array}$ \\
\hline 466 & 237 & 441 & 265 & 414 \\
(CF.02.BA) & (CC.02.IC) & (CF.01.GC) & (CD.01.EA) & (CE.02.LC) \\
\hline 385 & 28 & 106 & 305 & 271 \\
(CE.02.CA) & (CA.01.JA) & (CB.01.HA) & (CD.02.DB) & (CD.01.GA) \\
\hline 479 & 230 & 85 & 48 & 165 \\
$(\mathrm{CF} .02 . \mathrm{FB})$ & (CC.02.GB) & (CB.01.AA) & (CA.02.BC) & (CB.02.MC) \\
\hline
\end{tabular}


Tabel 3. Isi Task Order pada Percobaan 2

\begin{tabular}{|c|c|c|c|c|}
\hline $\begin{array}{c}553 \\
\text { (CG.02.CA) }\end{array}$ & $\begin{array}{c}251 \\
(\mathrm{CC} .02 . \mathrm{NB})\end{array}$ & $\begin{array}{c}37 \\
\text { (CA.01.MA) }\end{array}$ & $\begin{array}{c}326 \\
(\mathrm{CD} .02 . \mathrm{KB})\end{array}$ & $\begin{array}{c}407 \\
\text { (CE.02.JB) }\end{array}$ \\
\hline $\begin{array}{c}213 \\
\text { (CC.02.AC) }\end{array}$ & $\begin{array}{c}191 \\
\text { (CC.01.HB) }\end{array}$ & $\begin{array}{c}438 \\
\text { (CF.01.FC) }\end{array}$ & $\begin{array}{c}30 \\
\text { (CA.01.JC) }\end{array}$ & $\begin{array}{c}452 \\
\text { (CF.01.KB) }\end{array}$ \\
\hline $\begin{array}{c}279 \\
\text { (CD.01.IC) }\end{array}$ & $\begin{array}{c}159 \\
\text { (CB.02.KC) }\end{array}$ & $\begin{array}{c}361 \\
\text { (CE.01.IA) }\end{array}$ & $\begin{array}{c}118 \\
\text { (CB.01.LA) }\end{array}$ & $\begin{array}{c}239 \\
\text { (CC.02.JB) }\end{array}$ \\
\hline $\begin{array}{c}441 \\
\text { (CF.01.GC) }\end{array}$ & $\begin{array}{c}274 \\
\text { (CD.01.HA) }\end{array}$ & $\begin{array}{c}501 \\
\text { (CF.02.MC) }\end{array}$ & $\begin{array}{c}55 \\
\text { (CA.02.EA) }\end{array}$ & $\begin{array}{c}573 \\
\text { (CG.02.IC) }\end{array}$ \\
\hline
\end{tabular}

Tabel 4. Isi Task Order pada Percobaan 3

\begin{tabular}{|c|c|c|c|c|}
\hline $\begin{array}{c}139 \\
\text { (CB.02.EA) }\end{array}$ & $\begin{array}{c}298 \\
\text { (CD.02.BA) }\end{array}$ & $\begin{array}{c}274 \\
\text { (CD.01.HA) }\end{array}$ & $\begin{array}{c}54 \\
\text { (CA.02.DC) }\end{array}$ & $\begin{array}{c}181 \\
\text { (CC.01.EA) }\end{array}$ \\
\hline $\begin{array}{c}561 \\
\text { (CG.02.EC) }\end{array}$ & $\begin{array}{c}72 \\
\text { (CA.02.JC) }\end{array}$ & $\begin{array}{c}556 \\
\text { (CG.02.DA) }\end{array}$ & $\begin{array}{c}95 \\
\text { (CB.01.DB) }\end{array}$ & $\begin{array}{c}409 \\
\text { (CE.02.KA) }\end{array}$ \\
\hline $\begin{array}{c}276 \\
\text { (CD.01.HC) }\end{array}$ & $\begin{array}{c}369 \\
(\mathrm{CE} .01 . \mathrm{KC})\end{array}$ & $\begin{array}{c}616 \\
\text { (CH.02.BA) }\end{array}$ & $\begin{array}{c}566 \\
\text { CG.02.GB) }\end{array}$ & $\begin{array}{c}271 \\
\text { (CD.01.GA) }\end{array}$ \\
\hline $\begin{array}{c}4 \\
\text { (CA.01.BA) }\end{array}$ & $\begin{array}{c}424 \\
\text { (CF.01.BA) }\end{array}$ & $\begin{array}{c}546 \\
\text { (CG.01.NC) }\end{array}$ & $\begin{array}{c}502 \\
\text { (CF.02.NA) }\end{array}$ & $\begin{array}{c}446 \\
\text { (CF.01.IB) }\end{array}$ \\
\hline
\end{tabular}

Tabel 5. Isi Task Order pada Percobaan 4

\begin{tabular}{|c|c|c|c|c|}
\hline $\begin{array}{c}226 \\
\text { (CC.02.FA) }\end{array}$ & $\begin{array}{c}374 \\
\text { (CE.01.MB) }\end{array}$ & $\begin{array}{c}578 \\
\text { (CG.02.KB) }\end{array}$ & $\begin{array}{c}138 \\
\text { (CB.02.DC) }\end{array}$ & $\begin{array}{c}447 \\
\text { (CF.01.IC) }\end{array}$ \\
\hline $\begin{array}{c}485 \\
\text { (CF.02.HB) }\end{array}$ & $\begin{array}{c}83 \\
\text { (CA.02.NB) }\end{array}$ & $\begin{array}{c}365 \\
\text { (CE.01.JB) }\end{array}$ & $\begin{array}{c}314 \\
\text { (CD.02.GB) }\end{array}$ & $\begin{array}{c}155 \\
\text { (CB.02.JB) }\end{array}$ \\
\hline $\begin{array}{c}488 \\
\text { (CF.02.IB) }\end{array}$ & $\begin{array}{c}22 \\
\text { (CA.01.HA) }\end{array}$ & $\begin{array}{c}596 \\
(\mathrm{CH} .01 . \mathrm{CB})\end{array}$ & $\begin{array}{c}358 \\
\text { (CE.01.HA) }\end{array}$ & $\begin{array}{c}106 \\
\text { (CB.01.HA) }\end{array}$ \\
\hline $\begin{array}{c}158 \\
(\mathrm{CB} .02 . \mathrm{KB})\end{array}$ & $\begin{array}{c}341 \\
\text { (CE.01.BB) }\end{array}$ & $\begin{array}{c}114 \\
\text { (CB.01.JC) }\end{array}$ & $\begin{array}{c}235 \\
\text { (CC.02.IA) }\end{array}$ & $\begin{array}{c}468 \\
\text { (CF.02.BC) }\end{array}$ \\
\hline
\end{tabular}

Kinerja masing-masing algoritma di setiap percobaan diberikan di Tabel 6.

Tabel 6. Perbandingan Kinerja Algoritma pada Empat Percobaan

\begin{tabular}{lccccc}
\hline $\begin{array}{c}\text { Algoritma } \\
\text { Heuristik }\end{array}$ & $\begin{array}{c}\text { Jarak Tempuh } \\
\text { Percobaan 1 } \\
\text { (meter) }\end{array}$ & $\begin{array}{c}\text { Jarak Tempuh } \\
\text { Percobaan 2 } \\
\text { (meter) }\end{array}$ & $\begin{array}{c}\text { Jarak Tempuh } \\
\text { Percobaan 3 } \\
\text { (meter) }\end{array}$ & $\begin{array}{c}\text { Jarak Tempuh } \\
\text { Percobaan 4 } \\
\text { (meter) }\end{array}$ & $\begin{array}{c}\text { Rataan } \\
\text { Jarak Tempuh (meter) }\end{array}$ \\
\hline S-shape & 353.70 & 365.60 & 375.30 & 408.30 & 375.725 \\
Return & 356.20 & 324.60 & 428.80 & 405.80 & 378.850 \\
Mid-point & 391.95 & 342.85 & 390.55 & 383.05 & 377.100 \\
Largest gap & $\mathbf{3 2 4 . 7 0}$ & $\mathbf{3 1 2 . 1 0}$ & $\mathbf{3 6 3 . 3 0}$ & $\mathbf{3 4 5 . 8 0}$ & $\mathbf{3 3 6 . 4 7 5}$ \\
Aisle by aisle & 347.95 & 337.45 & 376.05 & 364.05 & 356.375
\end{tabular}

Berdasarkan hasil perhitungan dari empat percobaan, ditemukan bahwa algoritma heuristik yang selalu menghasilkan jarak tempuh terpendek di gudang kajian adalah algoritma largest gap. Jika dibandingkan dengan metode yang saat ini digunakan perusahaan, yang secara rata-rata menghasilkan jarak tempuh sebesar 386.975 maka implementasi algoritma largest gap mengakibatkan penghematan jarak tempuh rata-rata sebesar 50.5 meter. Jika aktivitas picking ini dilakukan sebanyak 8-12 kali per hari, maka total jarak tempuh yang dapat dihemat per hari berkisar antara 404 - 606 meter. Jika menggunakan riset Bartholdi dan Hackman (2011), yang menyatakan bahwa order picking berperan pada $70 \%$ waktu dan $55 \%$ biaya, maka penghematan yang dilakukan ada di kisaran 7-8\%, meskipun tidak diteliti secara detil pada studi ini. 
Tata letak gudang di perusahaan kajian memiliki dua blok yaitu blok $\mathrm{X}$ dan blok Y. Blok $\mathrm{X}$ memiliki 24 rak penyimpanan dengan total panjang sebesar 24 meter. Sedangkan blok Y memiliki 18 rak penyimpanan dengan total panjang sebesar 18 meter. Algoritma largest gap cenderung baik diterapkan pada gudang yang memiliki blok relatif panjang. Largest gap akan menentukan rute berdasarkan jarak terjauh lokasi pengambilan dalam sebuah lorong. Semakin panjang blok atau lorong yang harus dilalui picker maka semakin jelas gap yang terlihat antar lokasi pengambilan dalam sebuah lorong. Apabila lorong yang dilalui oleh picker tidak terlalu panjang, maka gap yang dihasilkan tidak signifikan sehingga penerapan metode largest gap menjadi kurang baik.

\section{Kesimpulan}

Beberapa kesimpulan yang dapat ditarik dari penelitian ini adalah:

1. Algoritma heuristik untuk gudang dengan karakteristik two-cross aisles telah berhasil dikembangkan dari algoritma heuristik untuk gudang dengan karakteristik three-cross aisles.

2. Algoritma heuristik yang dikembangkan telah diimplementasikan pada sebuah gudang dengan layout two-cross aisles. Hasil implementasi menunjukkan bahwa penerapan algoritma largest gap memberikan jarak perpindahan paling minimum. Jika dibandingkan dengan kebijakan penentuan rute yang digunakan saat ini, maka terdapat penghematan jarak dari sebelumnya rata-rata sejauh 386.975 meter, menjadi rata-rata sejauh 336.475 meter atau memiliki selisih rata-rata sejauh 50.5 meter. Jika diasumsikan penghematan jarak berbanding lurus dengan ongkos pemindahan material maka diperoleh penghematan dengan persentase yang sama.

3. Perlu dikaji konsistensi algoritma untuk macam-macam ukuran blok di gudang, mengingat karakteristik gudang kajian pada penelitian ini memiliki ukuran blok yang relatif panjang. Pada Gudang yang ukuran blok tidak terlalu panjang, besar gap saat penentuan largest gap dapat saja tidak signifikan, sehingga algoritma ini akan sama baiknya dengan algoritma lain.

\section{Daftar Pustaka}

Bartholdi, J.J dan Hackman, S.T, (2008), Warehouse and Distribution Science, Georgia Institute of Technology.

Bartholdi, J.J dan Hackman, S.T, (2011), Warehouse and Distribution Science, The Supply Chain and Logistic Institute. Atlanta: School of Industrial and System Engineering.

De Koster, R dan Roodbergen, K.J, (2007), Design and Control of Warehouse Order Picking: A Literature Review, European Journal of Operation Research, 182, pp. 481-501.

Dukic, G. dan Oluic, C, (2007), Order Picking Methods: Improving Order - Picking Efficiency, International Journal of Logistics System and Management, 3, pp. 451 - 460.

Habazin, J., Glasnovic, A., dan Bajor, I., (2017), Order Picking Process in Warehouse: Case Study of Dairy Industry in Croatia, Promet Traffic \& Transportation, 29 (1), pp. 57-65.

Hall, R.W, (1993), Distance approximations for routing manual pickers in a warehouse. IIE Transactions, 25(4), 76-87.

Lambert, D.M dan Stock, J.R, (2001), Strategic Logistic Management, Edisi Keempat, New York.

Oktarina, R. dan Wini, (2008), Penentuan Rute Order Picking dengan Menggunakan Metode Heuristic (Studi Kasus: PT'X”). Tugas Akhir Teknik Industri, Universitas Widyatama.

Roodbergen K.J, (2001), Layout and Routing Methods for Warehouses, Ph.D. Series Research in Management. 